\title{
A análise linguística intercultural em eventos de formação de professoras de Português como Língua de Acolhimento
}

\author{
Flávia Azambuja* \\ Clara Dornelles** \\ Everton Vargas da Costa***
}

Resumo

O objetivo deste trabalho é investigar como a prática de análise linguística acontece na perspectiva intercultural em eventos de formação de professoras de Português como Língua de Acolhimento (PLAc). Para isso, nos ancoramos no conceito de eventos de formação (COSTA, 2013; 2018; LEMOS, 2014), de análise linguística (MENDONÇA, 2006; 2007a e b) e de interculturalidade (JANZEN, 2005; TORQUATO, 2014; 2016). A pesquisa centra-se na geração de dados e análise de cunho etnográfico, no contexto de um curso de imersão on-line ofertado no âmbito do projeto Núcleo de Apoio à Aprendizagem Intercultural de Português como Língua Adicional e de Acolhimento (NAAIPLAA), em ações de docência compartilhada (LEMOS, 2014; SCHLATTER; COSTA, 2020). A turma é constituída por 30 estudantes e as professoras são graduandas e egressas do curso de Letras da Universidade Federal do Pampa (Unipampa), com experiências presenciais em ensino de PLAc. Neste artigo, discutimos um evento de formação em que a análise linguística se torna relevante durante uma aula síncrona via Google Meet. Os resultados mostram que práticas que envolvem a análise linguística intercultural se caracterizam pela reflexão colaborativa sobre estranhamentos

\footnotetext{
* Universidade Federal do Pampa (Unipampa). Mestra em Ensino pela Unipampa. Professora da Prefeitura Municipal de Bagé. Cocoordenadora do Laboratório de Leitura e Produção Textual da Unipampa. ORCID: https://orcid.org/0000-0001-8674-5342.

** Universidade Federal do Pampa (Unipampa). Doutora em Linguística Aplicada. Professora associada da Unipampa. Professora no curso de Letras/Línguas Adicionais (Inglês e Espanhol) e Respectivas Literaturas e no mestrado profissional em Ensino de Línguas (MPEL) da Unipampa. ORCID: https://orcid.org/0000-0001-6472-7354.

*** Framingham State University (EUA). Doutor em Linguística Aplicada. Professor adjunto de Espanhol e Português na Framingham State University. ORCID: https://orcid.org/0000-0003-4377-763X.
} 
ocasionados pelos usos linguísticos, o que impacta a aprendizagem de alunos e professoras. Os resultados também apontam para a preponderância da participação dos estudantes em eventos de formação, em aulas de PLAc que visam à análise linguística intercultural, e indicam que a análise linguística se concretiza como intercultural em ações interacionais entre professores e estudantes, gerando aprendizagens para todos os participantes.

Palavras-chave: Eventos de formação. Análise linguística intercultural. Português como Língua de Acolhimento.

\title{
Linguistic analysis in teacher's education events
}

\begin{abstract}
The goal of this paper is to investigate how the practice of linguistic analysis manifests from an intercultural perspective in training events of teachers of Portuguese as a host language (PHL). To this end, we base our analysis on the concept of teacher's education events (COSTA, 2013; 2018; LEMOS, 2014), linguistic analysis (MENDONÇA, 2006; 2007) and interculturality (JANZEN, 2005; TORQUATO, 2014; 2016). This ethnograhic-based qualitative research focuses on data generation and analysis in the context of an online immersive course offered under the Project NAAIPLAA, in coteaching actions (LEMOS, 2014; SCHLATTER; COSTA, 2020). The class analysed consists of 30 students and the teachers are undergraduates and graduates in Letras da Universidade Federal do Pampa (Unipampa), with some face-to-face experience in PHL. In this article, we discuss a teacher's education event in which linguistic analysis becomes relevant during a synchronous class via Google Meet. The results show that practices involving intercultural linguistic analysis are
\end{abstract}


characterized by the collaborative reflection on the perceptions caused by linguistic uses, which impacts how students and teachers learn. This study points out the relevance of student participation in teacher's education events, when intercultural linguistic analysis is at play in PHL classes, and shows that linguistic analysis, approached as intercultural in interactions between teachers and students, provides all the participants with learning opportunities.

Keywords: Teacher's education events. Intercultural linguistic analysis. Portuguese as a Host Language.

Recebido em: 08/03/2021 // Aceito em: 28/03/2021. 


\section{Introdução}

Sabemos que a chegada a um novo país apresenta inúmeras dificuldades, entre elas está a aprendizagem de uma nova língua para que intercambistas, imigrantes ou refugiados possam realizar as mais diversas atividades ligadas ao trabalho, estudo ou lazer (EUSÉBIO; REBOUÇAS; HONORATO, 2014). Para a grande maioria dos estrangeiros a quem ensinamos e com quem aprendemos a ensinar, nas áreas de Português como Língua Adicional (PLA) e de Acolhimento ${ }^{1}$ (PLAc), a língua é o recurso principal para a construção de suas vidas no aqui e agora. Esse cenário se complexificou em 2020 com a pandemia da Covid-19, sobretudo com a suspensão de aulas presenciais por um período indeterminado.

Neste artigo, tratamos de parte dos resultados de uma pesquisa qualitativa de cunho etnográfico que integrou professoras de PLAc com diferentes experiências de formação. Pretendemos discutir, centralmente, como a problematização sobre análise linguística em eventos de formação influencia o trabalho em sala de aula, norteados pela pergunta de pesquisa: Como a análise linguística aliada à interculturalidade promove situações propícias para aprender a ensinar? Para responder a ela, apoiamo-nos no conceito de eventos de formação, que diz respeito a situações propícias para que o professor aprenda a ensinar, seja em contextos formais e monitorados, falando com colegas, planejando e implementando aulas em parceria, ou outras atividades que podem impactar as ações pedagógicas futuras (LEMOS, 2014; COSTA, 2018).

\footnotetext{
1 Quem sai do seu país de origem, por diferentes motivos, precisa, como evidencia Grosso (2010, p. 6), "agir linguisticamente de forma autônoma, num contexto que não lhe é familiar". O ensino de PLAc pretende que os aprendizes possam atuar na nova realidade, considerando as dificuldades pelas quais um refugiado passa. A perspectiva da Língua de Acolhimento no ensino possibilita que o aprendiz, sem desconsiderar sua história e cultura, acesse e seja interlocutor de discursos que visem à cidadania, viabilizando direitos e requerendo, em contrapartida, deveres.
} 
A análise linguística intercultural em eventos de formação de professoras de Português como Língua de Acolhimento

As ações de ensino e formação aqui focalizadas se desenvolveram no âmbito do projeto de extensão Núcleo de Apoio à Aprendizagem Intercultural de Português como Língua Adicional e de Acolhimento (NAAIPLAA), em que as professoras, além de ministrar aulas, têm oportunidades prévias de refletir acerca de conhecimentos teóricos e produzir materiais didáticos. O NAAIPLAA tem sua sede na Universidade Federal do Pampa (Unipampa), que está localizada em Bagé/RS, com cerca de 120 mil habitantes. Atualmente, a região recebe refugiados de diferentes lugares. A partir das discussões da equipe e das avaliações dos alunos estrangeiros a respeito dos cursos ofertados, em 2019, assumiu-se o desafio da construção de uma metodologia de ensino de PLAc que, sem perder o caráter intercultural das práticas do projeto, tivesse maior explicitação da gramática. Com base em tal desafio, a presente pesquisa procura descrever e analisar como o que chamamos de "análise linguística intercultural" molda eventos de formação nos quais professoras e alunos participantes da pesquisa se engajam.

Diante desse contexto, analisamos e discutimos as ações de duas professoras em docência compartilhada (LEMOS, 2014; COSTA; SCHLATTER, 2019), com enfoque em análise linguística. A aula fez parte do curso de nível básico a distância, chamado: "Português como Língua Adicional em Contexto de Imersão I'. Como o curso foi ofertado a distância, a turma incluiu imigrantes, intercambistas e interessados na língua portuguesa, residentes em diferentes regiões do Brasil e em outros países. Nossa discussão sobre análise linguística, nesta pesquisa, leva em conta a realidade dos alunos e suas necessidades. Assim, a análise linguística parte de textos que circulam socialmente, para que os estudantes possam compreender como aspectos linguísticos podem evidenciar questões culturais e mesmo interferir em relações de poder e justiça social. 
Na sequência, apresentamos a seção de referencial teórico, em que descrevemos a formação de professores pela lente qualitativa dos eventos de formação, e nossa compreensão de análise linguística, que parte de estudos do português como língua materna para integrar o ensino intercultural de português para estrangeiros. Após, apresentamos a metodologia que incluiu princípios de pesquisa qualitativa de cunho etnográfico, descrevendo o contexto de pesquisa, participantes e procedimentos para geração de dados. A discussão subsequente analisa um dado interacional entre professoras e alunos, em que a análise linguística intercultural proporciona momentos propícios de aprendizagem para os estudantes e professoras, seguida das considerações finais.

\section{A pesquisa sobre formação de professores de línguas adicionais}

O NAAIPLAA se constituiu como um laboratório colaborativo de prática de ensino, em que atuam graduandos em Letras - Línguas Adicionais (Inglês e Espanhol) e Respectivas Literaturas e também egressos do curso de Letras em português como língua materna, da mesma universidade. Os professores em formação do programa participam de modalidades como reuniões pedagógicas, sessões de planejamento e docência compartilhada. Para Bulla e Costa (2017, p. 228), a colaboração entre professores pode ser uma estratégia de formação: “[...] a perspectiva colaborativa de formação de professores centra-se em atividades como grupos de estudos, produção coletiva de materiais didáticos, elaboração de projetos pedagógicos, entre outros". Portanto, investigar a formação no NAAIPLAA pode lançar luzes para a reflexão e avaliação sobre modalidades colaborativas de formação. 
A análise linguística intercultural em eventos de formação de professoras de Português como Língua de Acolhimento

Para Costa $(2013$; 2018), a formação é uma prática que nunca se esgota, visto que é um processo que se dá em constante colaboração na prática pedagógica. Para pensar nesse aspecto da formação, ancoramo-nos no conceito, proposto por Costa (2013) e revisado por Costa (2018), de "evento de formação". Segundo o autor, esses eventos são:

[...] um momento propício para aprender a ensinar, e, em sua constituição, são fundamentais as ações desempenhadas pelos participantes de solicitar ajuda e de narrar experiências prévias relacionadas a práticas de sala de aula. $\mathrm{O}$ engajamento nos eventos analisados molda a experiência dos participantes como agentes formadores e em formação. (COSTA, 2018, p. 21).

Portanto, sempre que um professor participa de um momento com potencialidade para aprender a ensinar e demonstra engajamento, solicitando ou ofertando ajuda, narrando experiências ou propondo parcerias, colabora para a sua aprendizagem e dos colegas, o que pode ser analisado como um evento de formação. Costa e Schlatter (2019) acreditam que a prática é o aspecto determinante para se pensar em formação de professores; é no dia a dia das práticas relacionadas à profissão docente que os professores podem refletir sobre suas ações e ideias por meio de discussões organizadas com o auxílio de teorias, narrativas de experiência, pedidos e ofertas de ajuda e proposição de parcerias. Portanto, evento de formação é um conceito etnográfico, dependente da interpretação do pesquisador por meio de pistas interacionais, estudadas a partir do enquadre de dois ou mais participantes que se engajam em interações acerca de um tópico pedagógico, com um propósito para tal engajamento e com possíveis resultados observáveis (COSTA, 2013; 2018). Além disso, os eventos de formação se 
caracterizam pelo seu caráter situado, ou seja, servem como lócus para as culturas de aprender a ensinar em locais específicos e colocam os professores como agentes centrais para a construção dessas culturas (COSTA, 2018).

Lemos (2014) revisa o conceito inicialmente proposto por Costa (2013) e o reformula como "momento em que os participantes aprendem a ensinar e a ser professor em um determinado contexto" (LEMOS, 2014, p. 113). A asserção baseia-se na observação do trabalho on-line, em interações síncronas e assíncronas, que possibilitou o rastreamento de discussões em contextos de planejamento entre as participantes até a verificação do uso das aprendizagens durante as aulas em docência compartilhada. Lemos (2014) sintetiza as ações que, em seu contexto de análise, geraram eventos de formação:

"convidar para organizar atividades, convidar para
analisar atividades, expor um problema, pedir ajuda
para fazer algo, pedir ajuda para discutir o que foi feito,
pedir ajuda para compreender algo, resolver problemas
emergentes e discordar". (LEMOS, 2014, p. 90).

Desse modo, a visão de formação que alicerça este trabalho valoriza o papel das experiências dos participantes e a mobilização de seus conhecimentos no sentido de aprender a ensinar. Contextos como o NAAIPLAA constituem-se como espaços de

incentivo e valorização da interlocução com o outro e da construção de (co)autoria, em que empreendimentos comuns são construídos conjuntamente em práticas não finitas, sendo as possibilidades de identidades abertas e fluidas". (COSTA; SCHLATTER, 2019, p. 556)

Em tais contextos, a diversidade de modalidades de formação é o que propicia interações entre professores, o que 
A análise linguística intercultural em eventos de formação de professoras de Português como Língua de Acolhimento

leva a aprendizagens produtivas. Costa $(2013 ; 2018)$, Lemos (2014) e Costa e Schlatter (2019) verificam, em suas pesquisas, a existência de diferentes modalidades de formação: contextos de aprendizagem mais monitorados, como seminários e reuniões, trabalho em parcerias; iniciativas que promovem a colaboração, como tutorias e docência compartilhada; e situações menos formais, como conversas na sala dos professores. Quando programas de ensino de línguas investem em diversificar suas modalidades de formação, as interações entre os pares terão potencial para tornarem-se eventos de formação.

Neste artigo, concentramo-nos na modalidade docência compartilhada, em situação de aula síncrona. Schlatter e Costa (2020) argumentam que a docência compartilhada favorece a) o trabalho em parceria entre professores mais e menos experientes, que são convidados a participarem ativa e criticamente na negociação de suas próprias identidades; e b) a construção de uma relação de igualdade existencial e epistêmica entre professores, orientados pela visão de que todos são capazes e podem contribuir e que possuem diferentes perspectivas e repertórios de conhecimentos "igualmente valiosos e úteis na profissão de professor e [que], portanto, devem ser compartilhados" (KORHONEN et al., 2017, p. 161). Na seção seguinte, tratamos da abordagem linguístico-pedagógica do NAAIPLAA.

\section{Aproximando análise linguística e interculturalidade}

O projeto NAAIPLAA tem uma trajetória de cinco anos e, desde o princípio, a interculturalidade é um aspecto estruturante das ações pedagógicas realizadas pelo seu corpo docente (BERGAMASCO, 2018; MORO, 2019). O grupo compreende 
interculturalidade a partir de Janzen (2005) e Torquato (2014; 2016), que, respaldados nos estudos do Círculo de Bakhtin, entendem o "encontro intercultural" como a interação entre pessoas com lugares históricos, sociais e culturais distintos e interculturalidade como um movimento cíclico, em que a cultura (visão de mundo e conjunto de valores) é percebida como híbrida e fluida, e não homogênea, como quer a visão tradicional, que se fixa em estereótipos (JANZEN, 2005; TORQUATO, 2014; 2016).

No encontro intercultural, conforme os autores, com base no Círculo de Bakhtin, deixamos de olhar o mundo estritamente a partir do nosso ponto de vista e nos colocamos no lugar do outro para depois retornarmos ao nosso lugar (empatia), o que nos permite enxergar no outro o que ele não vê, assim como ele vê em nós o que não percebemos (exotopia), devido a um excedente ou distanciamento de visão que apenas o outro pode ter. Esse processo, de diálogo/conflito intercultural, quando realmente acontece, nos modifica, e nunca retornamos ao mesmo lugar. Para Torquato (2016, p. 432-433), “[...] a alteridade cultural é essencial à constituição de novos olhares sobre a própria cultura. Esses novos olhares, vale destacar, são promovidos no contexto do diálogo com o outro", mobilizando relações sociais/de poder associadas a práticas letradas que compõem o repertório cultural de cada grupo.

Janzen (2005) advoga pela natureza dialógica e, portanto, intercultural, da linguagem, que se constitui em aproximações e distanciamentos do outro, configurados em distintas práticas de letramentos, dos diferentes grupos em diferentes contextos (TORQUATO, 2016). O acesso a diferentes práticas letradas é também uma característica do encontro intercultural, já que faz 
A análise linguística intercultural em eventos de formação de professoras de Português como Língua de Acolhimento

com que os envolvidos se coloquem em situações distintas das que estão acostumados, o que pode gerar conflitos, uma vez que pode mobilizar ações invisíveis aos participantes, ou expectativas a eles estranhas, que requerem diálogo para reconhecer e, quando necessário, minimizar as diferenças.

Além de vivenciarem mudanças culturais e linguísticas, os estrangeiros, sobretudo imigrantes e refugiados, passam também por grandes mudanças no campo profissional, o que, por sua vez, impacta os recursos simbólicos e econômicos de que podem lançar mão no novo país. Por isso, o projeto do NAAIPLAA passou a considerar, desde 2017, a necessidade específica do ensino de PLAc (GROSSO, 2010), para constituir uma metodologia intercultural de ensino-aprendizagem estruturada em movimentos de empatia e exotopia. Esse movimento leva em consideração as culturas e os propósitos dos aprendizes, podendo influenciar a sua adaptabilidade no novo país.

Outro aspecto relacionado à metodologia intercultural de ensino-aprendizagem diz respeito à presença de outras línguas na sala de aula de PLAc, sejam elas maternas e/ou outras línguas adicionais. A pesquisa de Eusébio, Rebouças e Honorato (2014), com alunos haitianos, ressalta a importância do crioulo ou francês, visto que os alunos interagiam, se ajudavam com traduções, o que, para os professores envolvidos, foi importante na aquisição do português. Além disso, Nunes, Silva e Silva $(\mathrm{s} . \mathrm{d})^{2}$ ressaltam que outras línguas adicionais exercem forte influência na aprendizagem de uma nova língua, e isso não pode ser desconsiderado pelo professor. Ao invés de evitar o uso, é importante que entenda a influência e a considere que comparálas pode constituir o que Travaglia (1995) chama de gramática 
contrastiva, ${ }^{3}$ a análise de duas ou mais línguas ao mesmo tempo, estabelecendo comparações entre elas. Ao comparar o uso de línguas distintas, buscando por padrões de uma na outra, o aprendiz realiza o que chamamos de análise linguística intercultural. $\mathrm{Na}$ comparação de padrões linguísticos, há a materialização de determinada(s) cultura(s) que também vai/vão ser comparada(s). Portanto, a língua materna ou outra(s) língua(s) falada(s), em contextos específicos, funcionam como pontes para a reflexão linguística. Essas práticas se constituem em interculturais na medida em que se desenvolvem em eventos que buscam explicitar diferenças nas visões sobre os usos e aprendizagens da(s) língua(s), pautadas em representações culturais, sendo constitutivas da "análise linguística intercultural".

Nossa construção do conceito de "análise linguística intercultural" integra a perspectiva de interculturalidade acima apresentada com o conceito de "análise linguística" tipicamente associado ao ensino de português como língua materna. Conforme Mendonça (2006, p. 96), a análise linguística “[...] consiste num movimento de reflexão sobre o funcionamento da linguagem, que toma a produção de sentidos nos usos linguísticos como ponto essencial". Por meio dessa definição, é possível estabelecer relações entre a análise linguística e a prática social, visto que, nessa perspectiva, a reflexão sobre a língua se dá sempre por meio da análise do seu uso. Prática social, por sua vez, conforme Clark (1997), é entendida como ações conjuntas dos sujeitos, constituídas de modo mais ou menos institucionalizado, uma vez que são sempre codificadas e associadas a sentidos tácitos.

\footnotetext{
3 Embora haja estudos específicos sobre análise contrastiva na área de ensino de português para estrangeiros (ALMEIDA FILHO, 2001), optamos por nos basearmos em Travaglia (1995), porque tal perspectiva se alinha mais adequadamente à cultura de ensino no NAAIPLAA. Consideramos, no entanto, que a análise contrastiva como método de ensino de línguas adicionais tem um valor e uma história consolidados, e que, direta ou indiretamente, lançamos mão de seus pressupostos constantemente em aula.
} 
A análise linguística intercultural em eventos de formação de professoras de Português como Língua de Acolhimento

A análise linguística é uma atividade epilinguística ${ }^{4}$ que leva em consideração as práticas sociais e os contextos de variação (NEVES, 2004; BAGNO, 2001; 2007), em que os usos da língua se materializam. Por meio da prática de análise linguística, o professor pode orientar os aprendizes a refletir sobre os usos mais ou menos prestigiados e, assim, fazer suas escolhas de acordo com o contexto e seus objetivos, além de perceber aspectos gramaticais que evidenciam questões culturais. Por determinadas escolhas é possível perceber de que região o falante vem, a que interlocutor se dirige, entre outros aspectos. $\mathrm{O}$ falante estrangeiro precisará reconhecer os valores sociais dados pelos brasileiros aos usos, mas também lidar com preconceitos decorrentes de sua identidade linguística estrangeira, constituída nas escolhas linguísticas e prosódicas que faz.

Nesta pesquisa, investimos no conceito de análise linguística intercultural porque acreditamos ser relevante considerá-lo para trabalhar com os aspectos gramaticais aliados à interculturalidade no ensino de línguas adicionais. Segundo Mendonça (2007b), os recursos linguísticos e seu ensino em sala de aula devem estar atrelados ao projeto de dizer dos alunos. Para isso, devem considerar o gênero escolhido, seu objetivo, seu interlocutor, tom desejado pelo autor da produção, entre outros aspectos, o que se relaciona diretamente com a prática social e possibilita a emergência de reflexão sobre práticas de letramento distintas. Conforme Mendonça (2006), a análise linguística:

privilegia a produção em detrimento do reconhecimento e da reprodução de saberes; a expressão da subjetividade no lugar do silenciamento; o texto e não a frase como unidade básica do trabalho pedagógico; a linguagem

4 Atividade epilinguística, segundo Franchi (1991, p. 36), é uma "[...] prática que opera sobre a própria linguagem, compara as expressões, transforma-as, experimenta novos modos de construção canônicos ou não, brinca com a linguagem, investe as formas linguísticas de novas significações". 
como atividade e não como produto de tarefas, entre outros. (MENDONÇA, 2006, p. 98).

O aluno, ao ser colocado em uma situação de produção do seu texto e, portanto, do seu ponto de vista no mundo, ao invés de simplesmente reconhecer estruturas e reproduzir o que é dito pelo professor ou pelos materiais didáticos, é colocado em uma posição de protagonismo, de uso da língua em práticas sociais. No entanto, para que o professor de português para estrangeiros consiga colocar os alunos em posição de protagonismo, é importante que ele seja protagonista em sua prática, em seu planejamento e no trabalho com a prática de análise linguística intercultural, o que só é possível por meio de uma formação reflexivo-crítica e colaborativa, também estruturada sobre a perspectiva intercultural e com atitude aberta à aprendizagem constante, como se busca no contexto de pesquisa, como explicamos na próxima seção.

\section{Metodologia}

O presente artigo discute parte dos resultados de uma pesquisa qualitativa de cunho etnográfico realizada no NAAIPLAA, cujo objetivo é produzir materiais, planejar, implementar e avaliar ações relacionadas ao ensino/ aprendizagem de PLA e PLAc, em modalidades colaborativas de formação. Há três modalidades preponderantes no programa: reuniões para discussão sobre aulas e planejamentos; reuniões para discussão de teóricos; docência compartilhada. A equipe se reúne quinzenalmente para tratar dos cursos ofertados e, a partir dos relatos das aulas, define problemáticas para aprofundamento 
A análise linguística intercultural em eventos de formação de professoras de Português como Língua de Acolhimento

e discussão teórica. Em relação à docência compartilhada, duas professoras ou mais trabalham juntas em todas as etapas do processo pedagógico, desde o planejamento de tarefas até suas implementações em aula e reflexão e avaliação sobre as aprendizagens de seus alunos e suas próprias.

O dado analisado neste artigo é parte de uma pesquisa mais extensa ${ }^{5}$ e foi gerado em ações pré-durante-pós-curso de "Português como Língua Adicional em Contexto de Imersão I", realizado pela plataforma Moodle e com aulas síncronas semanais pelo Google Meet. O planejamento de aulas e reuniões da equipe, via Google Drive e WhatsApp, começou em abril de 2020, e o curso ocorreu entre agosto e setembro. As aulas foram gravadas com o consentimento de 30 alunos, que preencheram um termo de consentimento livre e esclarecido, autorizando o uso das gravações e de suas produções na aula ou sobre o curso para fins de pesquisa.

Selecionamos, para este trabalho, um excerto em que a prática de análise linguística intercultural emerge a partir das ações dos estudantes, que constroem com as professoras reflexões sobre usos e aprendizagens de línguas. Além disso, o trabalho em docência compartilhada possibilita um momento de importante aprendizagem para uma das professoras, o que analisamos pela noção de eventos de formação. Como o curso foi ofertado a distância, a turma incluiu estudantes residentes em diferentes regiões do Brasil e em outros países. No excerto analisado, interagem uma estudante de pós-graduação francófona, dois alunos hispanofalantes e duas docentes. Uma das professoras é formada em Letras - Línguas Adicionais (Inglês e Espanhol) e

\footnotetext{
5 Trabalho de Conclusão de Curso apresentado ao curso de Letras Línguas Adicionais - Inglês e Espanhol e Respectivas Literaturas da Universidade Federal do Pampa - Unipampa (AZAMBUJA, 2020). O TCC se deu por meio de uma pesquisaação, entendida como uma forma contínua, empírica e sistemática de aprimoramento da prática. (TRIPP, 2005).
} 
Respectivas Literaturas e atua no projeto desde 2017, enquanto a outra é formada em português, mestre em Ensino de Línguas, atua no projeto desde 2016 e, atualmente, é graduanda no mesmo curso que a primeira professora. Ambas realizaram seus Trabalhos de Conclusão de Curso em PLAc. ${ }^{6}$

$\mathrm{Na}$ próxima seção, analisamos um excerto de uma aula síncrona, em que ocorre a prática de análise linguística intercultural, enquanto um momento propício para a aprendizagem de uma das professoras emerge.

\section{Eventos de formação na prática de análise linguística em aula síncrona}

$\mathrm{Na}$ presente seção, passamos a analisar um dado interacional em que o trabalho pedagógico de análise linguística intercultural impacta a aprendizagem das professoras sobre como ensinar. No dia da aula, o tema foi a produção de um e-mail para encaminhamento do curriculum vitae para fins profissionais ou acadêmicos. As professoras planejaram a aula síncrona em conjunto. Nesse arranjo de docência compartilhada, uma professora atuava como titular, e uma como observadora, embora tivesse autorização para intervir sempre que julgasse pertinente. No Excerto 1, temos a interação da professora titular com alunos e também com a professora observadora. Nessa aula, os alunos poderiam refletir sobre graus de formalidade de expressões muito usadas em e-mails, tais como: "prezado(a)", "abraços", "segue em anexo", "atenciosamente" e o "até logo". Enquanto as professoras explicavam sobre o modo de se despedir

6 Um dos trabalhos trata sobre a alfabetização de alunos sírios, e o outro, de eventos de formação, no mesmo curso analisado neste artigo. 
em e-mails a possíveis empregadores, certos usos de expressões de despedidas se tornam relevantes para a discussão, o que gerou o comentário do aluno José. ${ }^{7}$

\section{Excerto 1}

\begin{tabular}{|c|c|c|}
\hline 1 & José & $\begin{array}{l}\text { es mais informal, mas qualquer pessoa pode falar, } \\
\text { depende do contexto também. Aqui }\end{array}$ \\
\hline 2 & & $\begin{array}{l}\text { em Ribeirão Preto a gente fala até para falar que até } \\
\text { logo. A gente se vê né? }\end{array}$ \\
\hline 3 & Ana & $\begin{array}{l}\text { na fala a gente usa muito o até né? No e-mail, em geral, } \\
\text { a gente não vai ver o até né? }\end{array}$ \\
\hline 4 & & A gente vai ver o até logo. \\
\hline 5 & Mara & $\begin{array}{l}\text { você que eu como que não encontrei sentido que a } \\
\text { gente diz até. Para mim isso não }\end{array}$ \\
\hline 6 & & $\begin{array}{l}\text { tem sentido. Porque na aula quando empezei a escutar } \\
\text { que (ininteligível) até, até. Eu }\end{array}$ \\
\hline 7 & & $\begin{array}{l}\text { fiquei como perdida, não entendia nada. Nada, um } \\
\text { sentido nisso. }\end{array}$ \\
\hline 8 & Ana & $\begin{array}{l}\text { É, mas eu acho que é de até logo mesmo, aí vira até. A } \\
\text { gente faz muito disso na língua. }\end{array}$ \\
\hline 9 & & $\begin{array}{l}\text { A gente usa termos menores, a gente abrevia. A gente } \\
\text { faz muito disso, acho que é uma }\end{array}$ \\
\hline 10 & & característica da língua. Até logo vira até. \\
\hline 11 & Caroline & $\begin{array}{l}\text { e eu também acho que tudo depende da cultura e do } \\
\text { idioma. As palavras que pra gente }\end{array}$ \\
\hline 12 & & $\begin{array}{l}\text { não dão sentido, mas pra vocês dão sentido. Então acho } \\
\text { que a gente tem que copiar né, }\end{array}$ \\
\hline 13 & & essa fala que tá informal e que vocês usam no dia a dia. \\
\hline 14 & Ana & $\begin{array}{l}\text { sim, eu acho que o principal é tentar entender pelo } \\
\text { contexto né? Tentar fazer sentido pelo }\end{array}$ \\
\hline
\end{tabular}

$\overline{7}$ Utilizamos pseudônimos para proteger a identidade dos participantes. 


\begin{tabular}{|c|c|c|}
\hline 15 & & $\begin{array}{l}\text { contexto, o que pode ser e quando não entender } \\
\text { perguntar porque eu acho que não tem }\end{array}$ \\
\hline 16 & & $\begin{array}{l}\text { nenhum problema, acho que as pessoas vão falar. Claro } \\
\text { que nem sempre elas conseguem }\end{array}$ \\
\hline 17 & & $\begin{array}{l}\text { explicar porque elas usam determinadas expressões, } \\
\text { mas elas vão de alguma forma }\end{array}$ \\
\hline 18 & & $\begin{array}{l}\text { explicar pra vocês, então isso pode ajudar também e } \\
\text { prestar a atenção o que as pessoas }\end{array}$ \\
\hline 19 & & $\begin{array}{l}\text { usam e como usam e é bem o que a Caroline disse tem } \\
\text { a ver com a cultura né. Aprender }\end{array}$ \\
\hline 20 & & $\begin{array}{l}\text { língua é aprender a cultura de um lugar também. Eu não } \\
\text { tenho como separar língua da }\end{array}$ \\
\hline 21 & & $\begin{array}{l}\text { cultura né e obviamente a gente sempre olha pra cultura } \\
\text { do outro a partir da nossa. }[\ldots]\end{array}$ \\
\hline 22 & & $\begin{array}{l}\text { Eu sempre vou comparar com a minha, acho que isso é } \\
\text { natural. Quando vocês contam }\end{array}$ \\
\hline 23 & & $\begin{array}{l}\text { alguma coisa também que é diferente pra gente, a gente } \\
\text { compara. Isso é natural, eu acho }\end{array}$ \\
\hline 24 & & $\begin{array}{l}\text { que o que não pode acontecer assim, o que a gente deve } \\
\text { evitar é julgar, é achar que é feio, }\end{array}$ \\
\hline 25 & & que errado né? \\
\hline 26 & José & outra expressão que se usa até mais, a gente se vê. \\
\hline 27 & Ana & a gente usa também até mais, a gente se vê, até. \\
\hline 28 & Mara & $\begin{array}{l}\text { é que eu entendi que a expressão e a palavra que se diz } \\
\text { falando oralmente, mas que não }\end{array}$ \\
\hline 29 & & se escreve. \\
\hline 30 & Ana & como assim do quê? Do "até" tu tá falando? \\
\hline 31 & Mara & $\begin{array}{l}\text { sim, porque isso não tem sentido, escrevendo pra uma } \\
\text { pessoa e dizendo até logo ou a }\end{array}$ \\
\hline 32 & & gente se vê, isso não tem sentido escrevendo. \\
\hline
\end{tabular}




\begin{tabular}{|c|c|c|}
\hline 33 & Ana & por que não? \\
\hline 34 & Mara & $\begin{array}{l}\text { isso é ilógico para mim. Isso tem como um sentido } \\
\text { visual, um contato presencial }\end{array}$ \\
\hline 35 & & para mim, para mim. \\
\hline 36 & Ana & $\begin{array}{l}\text { mas eu posso escrever uma mensagem no WhatsApp } \\
\text { combinando alguma coisa e escrever }\end{array}$ \\
\hline 37 & & $\begin{array}{l}\text { a gente se vê. E aí faz sentido, né? A gente vai combinar } \\
\text { alguma coisa, a gente vai se ver }\end{array}$ \\
\hline 38 & & $\begin{array}{l}\text { depois. Eu posso escrever um bilhete e dizer até mais } \\
\text { ou a gente se vê em algum momento }\end{array}$ \\
\hline 39 & & $\begin{array}{l}\text { que a gente vá se encontrar depois, então mesmo na } \\
\text { escrita ele pode aparecer, eu acho }\end{array}$ \\
\hline 40 & & $\begin{array}{l}\text { que vai depender do contexto, acho que no e-mail, a } \\
\text { gente se vê e o até mais não é tão }\end{array}$ \\
\hline 41 & & $\begin{array}{l}\text { usado, não faz tanto sentido, mas em outros contextos } \\
\text { pode acontecer. }\end{array}$ \\
\hline 42 & Mara & $\begin{array}{l}\text { é como em espanhol quando duas pessoas estão } \\
\text { comunicando e dizem mira, mira isso e }\end{array}$ \\
\hline 43 & & $\begin{array}{l}\text { como estou falando por teléfono. A gente se acostuma } \\
\text { com isso mas isso não tem lógico }\end{array}$ \\
\hline 44 & & $\begin{array}{l}\text { porque uma professora me disse, isso não tem lógica } \\
\text { porque você não pode estar falando }\end{array}$ \\
\hline 45 & & $\begin{array}{l}\text { com uma pessoa por telefone e dizer mira, mira. Você } \\
\text { pode escutar ou é coisa pra prestar }\end{array}$ \\
\hline 46 & & atenção, mas não pode dizer que mira. \\
\hline 47 & Ana & $\begin{array}{l}\text { mira é um marcador conversacional. A gente usa isso e } \\
\text { não quer dizer necessariamente }\end{array}$ \\
\hline 48 & & $\begin{array}{l}\text { que a pessoa tem que olhar. Se o falante usa e a gente } \\
\text { consegue compreender, eu não sei }\end{array}$ \\
\hline 49 & & se eu posso dizer que não faz sentido \\
\hline
\end{tabular}




\begin{tabular}{|c|c|c|}
\hline 50 & Mara & $\begin{array}{l}\text { como Caroline falou isso depende da cultura do idioma. } \\
\text { No meu caso, eu quero lembrar }\end{array}$ \\
\hline 51 & & $\begin{array}{l}\text { que eu sou francófona e que no francês usam pouca } \\
\text { abreviatura. E também eu falo }\end{array}$ \\
\hline 52 & & $\begin{array}{l}\text { espanhol. Eu não sou nativa no espanhol, eu aprendo } \\
\text { espanhol, então eu aprendo com }\end{array}$ \\
\hline 53 & & $\begin{array}{l}\text { regra e como diz, em uma escola, então de qualquer } \\
\text { jeito eu vou falar diferente que um }\end{array}$ \\
\hline 54 & & $\begin{array}{l}\text { hispanofalante. Eu vou falar com mais regra que um } \\
\text { nativo, porque um nativo fala como }\end{array}$ \\
\hline 55 & & $\begin{array}{l}\text { que naturalmente, é seu idioma, é diferente que uma } \\
\text { pessoa que aprende. É por isso que }\end{array}$ \\
\hline 56 & & disse isso, não é nada mal. \\
\hline 57 & Ana & $\begin{array}{l}\text { só um parentesinho também. Quando a gente pensa em } \\
\text { regras, associa com gramática }\end{array}$ \\
\hline 58 & & $\begin{array}{l}\text { normativa, mas a língua tem as suas regras, sempre. E } \\
\text { tudo que a gente faz a gente }\end{array}$ \\
\hline 59 & & $\begin{array}{l}\text { obedece a regras na língua. Então o nativo, ele também } \\
\text { obedece a regras, ele sabe as }\end{array}$ \\
\hline 60 & & $\begin{array}{l}\text { regras da língua dele e usa, muitas vezes do uso, da fala } \\
\text { e que talvez tu não saiba porque }\end{array}$ \\
\hline 61 & & $\begin{array}{l}\text { tu estuda de outra forma, mas tem regras também. Acho } \\
\text { que a Catarina quer falar alguma }\end{array}$ \\
\hline 62 & & coisa. \\
\hline 63 & Catarina & $\begin{array}{l}\text { Eu acho que eu entendo o que a Mara quer falar quando } \\
\text { a gente tá aprendendo alguma }\end{array}$ \\
\hline 64 & & $\begin{array}{l}\text { língua. Eu entendo isso por que as vezes eu passo. Por } \\
\text { exemplo, aprendendo inglês tem }\end{array}$ \\
\hline 65 & & $\begin{array}{l}\text { algumas expressões que se você traduz, porque no } \\
\text { começo a gente traduz. Você traduz }\end{array}$ \\
\hline
\end{tabular}




\begin{tabular}{|c|c|c|}
\hline 66 & & $\begin{array}{l}\text { pra sua língua materna não faz sentido mesmo. E aí } \\
\text { você tem que fazer um passo a mais }\end{array}$ \\
\hline 67 & & $\begin{array}{l}\text { que é entrar na cultura como vocês falaram até agora. E } \\
\text { conseguir entender aquilo a }\end{array}$ \\
\hline 68 & & $\begin{array}{l}\text { partir do outro, é um processo a mais, e eu passo por } \\
\text { isso, por exemplo phrasal verbs em }\end{array}$ \\
\hline 69 & & $\begin{array}{l}\text { inglês, se você traduzir eles não fazem sentido né, não } \\
\text { são lógicos. Então, mas enfim }\end{array}$ \\
\hline 70 & & $\begin{array}{l}\text { quando aplicados numa sentença, num contexto eles } \\
\text { passam a fazer e aí um passo. É }\end{array}$ \\
\hline 71 & & $\begin{array}{l}\text { difícil pra quem aprende uma segunda, uma terceira } \\
\text { língua entender. Eu entendo o que ela }\end{array}$ \\
\hline 72 & & quer falar a partir disso, né. \\
\hline 73 & Mara & isso mesmo \\
\hline 74 & Ana & $\begin{array}{l}\text { sim. Ainda mais quando tu estuda num espaço formal, } \\
\text { porque vão ter várias experiências }\end{array}$ \\
\hline 75 & & $\begin{array}{l}\text { diferentes. De repente a pessoa aprende a língua no uso, } \\
\text { aprendeu porque foi morar no }\end{array}$ \\
\hline 76 & & $\begin{array}{l}\text { país, mas quem aprende nesse espaço formal tem outra } \\
\text { perspectiva realmente. Acho que }\end{array}$ \\
\hline 77 & & $\begin{array}{l}\text { a Mari tá falando um pouco disso e do que a Catarina } \\
\text { fala também, eu entendo essa }\end{array}$ \\
\hline 78 & & $\begin{array}{l}\text { dificuldade, mas a gente tem que lembrar que não dá } \\
\text { pra separar a língua da cultura e }\end{array}$ \\
\hline 79 & & $\begin{array}{l}\text { que eu tenho que tentar me colocar nesse lugar que é } \\
\text { diferente e que tá tudo certo }[\ldots] \text { As }\end{array}$ \\
\hline 80 & & línguas são diferentes. \\
\hline 81 & Catarina & essa é a parte bonita de aprender. \\
\hline
\end{tabular}

Fonte: Azambuja (2020) 
O aluno José abre o excerto comentando a forma de despedida informal com a qual está familiarizado na cidade em que reside (linhas 1-2). A professora Ana amplia o comentário, propondo o enfoque em diferenças entre usos das expressões na escrita e na fala (linhas 3-4). A aluna Mara compartilha sua experiência pessoal com a expressão abreviada "até", enfatizando sua confusão com o uso e a aparente falta de sentido em tal uso pelos falantes de português com quem convive (linhas 5- 7). Ana explica que a abreviação de certas expressões é um processo comum no uso oral da língua portuguesa (linhas 8-10), o que abre espaço para a aluna Caroline ratificar a abordagem de Ana, atribuindo o fenômeno em foco à cultura na qual ocorre. Ana, então, direciona a conversa para a noção de uso em contexto (linhas 14-25) e para a própria experiência de aprendizagem de línguas, ao que Mara busca formular uma explicação lógica desde sua compreensão para o uso da expressão "até" baseada na noção de usos orais e escritos anteriormente levantada por Ana (linhas 28-29, 31-32), que, no entanto, instiga a aluna a explicar seu comentário (linha 33), ao que esta formula uma visão epistêmica sobre como vê o uso da expressão em pauta, argumentando não poder visualizar o sentido de "até" (linhas 25, 34). Ana então inicia uma explicação sobre as diferentes formas de uso na escrita de expressões coloquiais e lista exemplos de uso da expressão em diferentes tipos de texto (linhas 36-41). Mara complementa seu argumento comparando o uso de "até" em uma despedida com o uso de "mira" em espanhol ao telefone, o que, em sua perspectiva, não faz sentido, porque a comunicação não presencial não possibilita olhar alguma coisa. Nas linhas 47 a 49, Ana explicita a função gramatical que a expressão "mira" tem em espanhol e apresenta a noção linguística de marcador 
A análise linguística intercultural em eventos de formação de professoras de Português como Língua de Acolhimento

conversacional. Mara, finalmente, retoma o comentário de Caroline e enfatiza sua perspectiva de que a chave para entender o uso de um determinado item linguístico está em entender a cultura em que tal item é usado. Para isso, ela inicia uma reflexão sobre sua própria experiência como falante de sua língua materna e como falante de línguas adicionais, observando que, para um aprendiz de língua adicional, parece ser mais fácil estar consciente sobre regras de uso que os próprios falantes nativos da língua-alvo (linhas 50-56).

Nas linhas 36-41 e 42-46, há uma culminância da análise linguística, que ganha tons interculturais quando as participantes usam exemplos do contexto de uso e comparam o fenômeno das expressões abreviadas com outros idiomas, em alguns casos, suas línguas nativas. A professora em formação precisa mobilizar seus conhecimentos linguísticos e, ao fazer isso, amplia a conversa sobre um uso específico de expressão coloquial em português, "até", para uma discussão sobre os modos mais universais de funcionamento das línguas. Ana aproveita cada fala de Mara para promover mais um passo na reflexão sobre como as línguas funcionam, introduzindo, por fim, uma noção sobre regra e sobre falante nativo. Entre as linhas 57 e 62, ela delineia epistemologicamente como falantes nativos demonstram o seguimento de regras, o que parece se alinhar a uma visão de que a regra, para além de algo que se aprende explicitamente, ganha vida, de fato, na cultura dos falantes, conflitando com a visão de Mara, expressa anteriormente (linhas 50-56). Nesse ponto, a participante Catarina, que estava até então observando a interação, sinaliza o início de participação (linhas 61-62). Catarina redireciona seu comentário, ratificando a fala de Mara, ao dar um depoimento sobre a sua própria experiência 
ao aprender phrasal verbs em inglês (linhas 63-72). Para ela, é compreensível que um aprendiz de língua procure lógica comparativamente com seu idioma nativo e que somente o uso atento às nuances culturais provê a compreensão dos contextos e, portanto, dos itens linguísticos. Mara prontamente concorda com Catarina (linha 73). Ana se afilia à explicação de Catarina, agrega as noções de aprendizagem formal e informal e finaliza chamando a atenção para a importância de que, como aprendizes, os alunos prestem atenção nas nuances da cultura manifestadas na língua (linhas 74-80). Catarina, então, faz uma avaliação do que, ao longo da interação, tornou-se, em sua perspectiva, o tópico: a aprendizagem (linha 81).

Da pergunta geradora sobre o contexto em que o aluno José usa a língua portuguesa, Ana, gradualmente, guia a interação que aborda noções de contexto de uso, preponderância da cultura nas línguas, usos escritos e orais, lógica e regra, a perspectiva do falante nativo e do aprendiz e, finalmente, o próprio processo de aprendizagem de uma língua adicional. Ana constrói um caminho para a análise linguística intercultural por meio de explicações, comentários e perguntas para compreender o ponto de vista do outro, que parecem deixar Mara à vontade para compartilhar sua experiência e perspectivas sobre língua, lógica e regra. Mesmo que Ana introduza conceitos linguísticos que promovem uma visão de língua como parte essencial da cultura, Mara sente-se em um ambiente seguro para discordar e expressar desconforto com usos que, em princípio, não lhe parecem lógicos. Entre as linhas 30 e 62, as duas participantes interagem, buscando entendimento em torno do uso da expressão “até". Enquanto Mara traz uma perspectiva que pode parecer advir do senso comum, Ana introduz considerações linguísticas 
A análise linguística intercultural em eventos de formação de professoras de Português como Língua de Acolhimento

que não parecem convencer sua interlocutora. A intervenção de Catarina iniciada na linha 63 indica a Ana que Mara pode estar abordando a questão pela perspectiva de aprendiz de uma língua adicional que busca lógica no seu processo de aprendizagem, o que é prontamente ratificado por Mara. Essa intervenção permite que a conversa passe a abordar a questão da aprendizagem de línguas, não se limitando aos aspectos linguísticos do idioma aprendido.

O trabalho em docência compartilhada no NAAIPLAA oportuniza que uma professora (Catarina) possa observar o trabalho de uma colega (Ana) e intervir em situações em que a compreensão da professora sobre as posições dos estudantes possa ser menos perceptível. Ao ofertar ajuda à Ana, Catarina indica à colega uma nova possibilidade de interpretação do que analisa Mara, ao passo que ratifica Mara como uma participante plenamente ativa na construção da análise linguística intercultural. Finalmente, Ana sinaliza sua compreensão do tópico (linhas 74 a 80) levantado por Mara e reformula sua explicação, reforçando a importância de que, ao aprender uma língua, os estudantes estejam atentos às nuances culturais. Pode-se inferir, portanto, que a docência compartilhada contribui para que os alunos possam ter uma experiência de análise linguística intercultural adequada e que as professoras possam seguir se aperfeiçoando nessa abordagem.

As professoras participantes mobilizam a perspectiva intercultural de ensino para compreender posicionamentos dos estudantes, que, em princípio, se distanciam dos seus. Nesse contexto, "perguntar" se constitui como uma ação central para o encontro intercultural, como explicita a professora titular. A pergunta torna possível que Ana perceba o que para 
ela não é visível, uma vez que promove o movimento de empatia, o primeiro gesto para o acesso ao espaço exotópico, em que a diferença pode ser percebida, e o "ilógico" assume o status de "diferente". A professora titular também promove na própria explicação movimento de empatia, ao dizer que é natural comparar as diferenças entre as línguas: "Quando vocês contam alguma coisa também que é diferente pra gente, a gente compara" (linhas 22 e 23). O diálogo/conflito intercultural se desenvolve por meio das explicações dadas e solicitadas, o que torna possível à professora observadora compreender aspectos que, para a titular, estavam invisíveis e, a partir daí, intervir com sua própria experiência de aprendiz de línguas adicionais para avançar no diálogo intercultural: "E aí você tem que fazer um passo a mais que é entrar na cultura como vocês falaram até agora. E conseguir entender aquilo a partir do outro, é um processo a mais" (linhas 66 a 68). A docência compartilhada, na perspectiva intercultural, mostra-se, assim, uma modalidade de ensino propícia para a emergência de eventos de formação em que as professoras aprendem com os estudantes. ${ }^{8}$

A partir da análise do uso da expressão "até", trazida pelo aluno José, toda uma problemática será construída nessa aula, evidenciando que, nesse caso, o evento de formação começa a ser construído por esse aluno, com a participação de Mara e Caroline. Ao trazer uma expressão que ouve em seu cotidiano, José demonstra estar analisando a língua para além do que acontece somente em sala de aula, o que é incentivado por meio da análise linguística. Um diálogo/conflito intercultural se estabelece com Mara, que, ao assumir posição exotópica, não encontra lógica nesse uso (linhas 5 a 7). Caroline volta sua fala

8 Bergamasco (2018) reflete sobre o impacto do ensino de PLAc e das ações com os aprendizes na formação docente, em uma das experiências precursoras do NAAIPLAA. 
A análise linguística intercultural em eventos de formação de professoras de Português como Língua de Acolhimento

para o papel da cultura na construção de sentidos (linhas 11 a 13), em movimento de empatia. Mara ainda fala sobre uma dicotomia entre oralidade e escrita, para ela, alguns usos só são possíveis na oralidade (linhas 28 e 29). As falas dos alunos são mobilizadas por Ana para que possam discutir questões relacionadas ao funcionamento da língua. $\mathrm{O}$ evento de formação, iniciado pelos alunos, acontece com a intervenção de Catarina, que sintetiza o que Mara e Ana traziam de contribuição para a discussão e estabelece correlações entre as falas, por meio de exemplos de sua vivência como estudante de língua adicional (linhas 63 a 70). A fala de Catarina mobilizada pelos alunos e também pela professora Ana materializa o evento de formação. Imediatamente, Mara se afilia à posição de Catarina (linha 73), assim como Ana (linha 74), o que demonstra que Ana, nesse momento, aprendeu a ensinar.

Os autores que inicialmente propuseram a noção de eventos de formação (COSTA, 2013; 2018; LEMOS, 2014; COSTA; SCHLATTER, 2019) não analisaram a participação de alunos em sala de aula como fator de impacto para eventos de formação, limitando-se a interações entre professores, ou entre estes e coordenadores. $\mathrm{O}$ que observamos aqui nos convida a refletir sobre os múltiplos modos como a docência compartilhada impacta as ações dos participantes em sala de aula. Além disso, como os alunos exercem papéis importantes para a aprendizagem do professor e, finalmente, como a adoção da análise linguística intercultural, no ensino de línguas adicionais, proporciona um tipo de reflexão sobre a língua, em que os participantes percebem sua própria experiência como falantes e analistas dos usos da linguagem. 
Em síntese, os resultados mostraram que práticas que envolvem a análise linguística intercultural, no contexto do ensino de português para estrangeiros, se caracterizam por: (i) análise contrastiva dos usos da língua-alvo com a língua materna, mas também com outras línguas adicionais; (ii) reflexão colaborativa sobre estranhamentos ocasionados pelos usos linguísticos; (iii) reflexão sobre processos de aprendizagem de línguas maternas e adicionais que impactam a aprendizagem de alunos e professoras. A análise dos dados demonstra que o aspecto que diferencia a análise linguística intercultural de outras modalidades de análise linguística é a reflexão colaborativa sobre os estranhamentos ocasionados pelos usos linguísticos. Conforme explicitamos na seção 3, a prática de análise linguística se constitui em intercultural na medida em que se desenvolve em eventos que buscam explicitar diferenças nas visões sobre os usos e aprendizagens da(s) língua(s), pautadas em representações culturais. Nos dados, esses eventos ocorrem para solucionar divergências entre as visões de docentes e alunos sobre as línguas, tanto maternas quanto adicionais, e suas aprendizagens, por meio de ações que incluem explicações, comentários e perguntas sobre o ponto de vista do outro, mas também expressam discordância e desconforto, na tentativa de desfazer estranhamentos e compreender outra(s) lógica(s). Práticas como essas emergem quando se constituem eventos em sala de aula em que os participantes se sentem acolhidos para compartilhar suas dúvidas e pontos de vista, o que é possível quando os docentes agem para a construção de espaços colaborativos de aprendizagem. No caso dos dados, as ações que visam à interculturalidade acabam por propiciar formação também para as docentes, que não têm como prever 
A análise linguística intercultural em eventos de formação de professoras de Português como Língua de Acolhimento

quais questões os alunos trarão, nem qual esforço intercultural elas próprias terão que fazer para compreender outra(s) lógica(s) e considerá-la(s) em suas ações pedagógicas.

A seguir, apresentamos algumas considerações finais.

\section{Considerações finais}

A pergunta que norteou nossa pesquisa foi: como a análise linguística aliada à interculturalidade promove situações propícias para aprender a ensinar? Para responder a ela, apoiamo-nos nos conceitos de eventos de formação, interculturalidade e análise linguística, para a análise e discussão de um excerto de aula síncrona de PLAc compartilhada por duas docentes, observadora e titular, no contexto do NAAIPLAA, um projeto pautado em modalidades colaborativas de formação. Considerando o contexto de estudo, propusemos o conceito de “análise linguística intercultural”, observável a partir de eventos que buscam explicitar diferenças nas visões sobre os usos e aprendizagens da(s) língua(s), pautadas em representações culturais.

A análise do excerto de aula demonstrou que o evento de formação se materializou no momento em que a professora observadora, alinhada à perspectiva dos estudantes, integrou sua própria reflexão como aprendiz de línguas adicionais, possibilitando que a professora titular percebesse a lógica na reflexão sobre língua e aprendizagem de línguas proposta por uma das alunas. Foi esse o momento em que a professora demonstrou aprender algo novo em relação ao ensino da prática de análise linguística intercultural. 
A análise linguística intercultural em eventos de formação de professoras de Português como Língua de Acolhimento

Nesse sentido, o dado nos possibilita ampliar o olhar para a participação estudantil em eventos de formação. No caso específico, as ações que abrem espaço para que o evento de formação aconteça vêm dos estudantes, que fazem uso das oportunidades de participação construídas de modo colaborativo com as docentes. As ações dos participantes evidenciam estranhamentos culturais, gestos de empatia e tentativas de diminuir o distanciamento entre pontos de vista que partem de lugares distintos, mas que podem ser (re)conhecidos pelo outro. Essas práticas indicam que, quando as docentes agem para a construção de espaços colaborativos de aprendizagem, geram oportunidades para sua própria formação, já que lidam com a imprevisibilidade do que os alunos comentarão, o que implica um esforço intercultural delas próprias para compreender outra(s) lógica(s) e considerá-la(s) em suas ações pedagógicas.

Desse modo, enfatizamos a importância de que, em seu processo de formação, professores de PLAc aprendam a fazer análise linguística intercultural, colocando-se na perspectiva do estudante estrangeiro e considerando suas próprias aprendizagens de línguas adicionais, sobre o uso/aprendizagem de línguas diversas, sejam materna, estrangeiras ou adicionais. Esperamos que nosso estudo possa colaborar para o desenho de experiências relevantes de formação de professores de línguas, como a que discutimos, em que a análise linguística se concretiza como intercultural em ações interacionais "com" os estudantes, de modo que, assim, todos aprendem. 
A análise linguística intercultural em eventos de formação de professoras de Português como Língua de Acolhimento

\section{Referências}

ALMEIDA FILHO, José Carlos P. (org.) Português para estrangeiros: interface com o espanhol. 2. ed. Campinas, SP: Pontes, 2001.

AZAMBUJA, Flávia. A análise linguística em eventos de formação de professoras de português como língua adicional. 2020. 84 f. Trabalho de conclusão de curso. Universidade Federal do Pampa - Unipampa, Bagé, 2020.

BAGNO, Marcos. Nada na língua é por acaso: por uma pedagogia da variação linguística. São Paulo: Parábola Editorial, 2007.

BAGNO, Marcos. Português ou brasileiro? Um convite à pesquisa. São Paulo: Parábola Editorial, 2001.

BERGAMASCO, Gabriele. O ensino de português como língua de acolhimento para uma família síria refugiada em Bagé - RS. 2018. 29 f. Trabalho de conclusão de curso. Universidade Federal do Pampa - Unipampa, Bagé, 2018.

BULLA, Gabriela da Silva; COSTA, Everton Vargas da. Atividades colaborativas na formação de professores de português como língua adicional no Programa de Português para Estrangeiros da UFRGS. In: ENCONTRO INTERNACIONAL DE INVESTIGADORES DE POLÍTICAS LINGUÍSTICAS, 8., 2017, Florianópolis. Atas. Florianópolis, 2017. p. 226-236.

CLARK, Herbert H. Using language. Cambridge University Press, 1997.

COSTA, Everton Vargas da. Eventos de formação de professores de português como língua adicional: a organização das práticas e as trajetórias de participação em um estudo interpretativo sobre aprender a ensinar. 2018. 299 f. Tese (Doutorado em Linguística Aplicada) - Universidade Federal do Rio Grande do Sul, UFRGS, Porto Alegre, 2018. 
A análise linguística intercultural em eventos de formação de professoras de Português como Língua de Acolhimento

COSTA, Everton Vargas da. Práticas de formação de professores de português língua adicional em um instituto cultural brasileiro no exterior. 2013. 162 f. Dissertação (Mestrado em Estudos da Linguagem) - Universidade Federal do Rio Grande do Sul, UFRGS, Porto Alegre, 2013. Disponível em: <https://lume.ufrgs.br/handle/10183/72754>. Acesso em: 31 maio 2020.

COSTA, Everton Vargas da; SCHLATTER, Margarete. A interlocução com os pares na formação profissional e a construção da identidade do professor-autor-formador. Linguagem \& Ensino, [s. l.], v. 22, n. 3, p. 554-576, 2019. Disponível em: $<$ http://dx.doi.org/10.15210/rle.v22i3.17143> $>$. Acesso em: 22 maio 2020.

EUSÉBIO, Umberto; REBOUÇAS, Eduardo Melo; HONORATO, Natália Marques Alencar. Prática intercultural para o ensino de português a imigrantes haitianos no Brasil. In: CONGRESSO IBEROAMERICANO DE CIENCIA, TECNOLOGÍA, INNOVACIÓN Y EDUCACIÓN, Buenos Aires, Argentina, nov. 2014.

FRANCHI, Carlos. Gramática e criatividade. São Paulo: Secretaria da Educação/Coordenadoria de Estudos e Normas Pedagógicas - CENP, 1991.

GROSSO, Maria José dos Reis. Língua de acolhimento, língua de integração. Horizontes de linguística aplicada, [s. l.], v. 9, n. 2, p. 61-77, 2010. Disponível em: <http://periodicos.unb.br/ index.php/horizontesla/article/view/886/771>. Acesso em: 27 jun. 2020.

JANZEN, Henrique Evaldo. O Ateneu e Jakob von Gunten: um diálogo intercultural possível. 2005. 170 f. Tese (Doutorado em Letras) - Universidade de São Paulo, São Paulo, 2005.

KORHONEN, Hanna et al. Student teachers' experiences of participating in mixed peer mentoring groups of in-service and pre-service teachers in Finland. Teaching and Teacher 
A análise linguística intercultural em eventos de formação de professoras de Português como Língua de Acolhimento

Education, [s. l.], v. 61, p. 153-163, 2017. Disponível em: $<$ https://doi.org/10.1016/j.tate.2016.10.011>. Acesso em: 27 jun. 2020.

LEMOS, Fernanda Cardoso. A formação do professor para o ensino de língua adicional em ambientes digitais com docência compartilhada. 2014. 122 f. Dissertação (Mestrado em Letras) - Universidade Federal do Rio Grande do Sul, Porto Alegre, 2014.

MENDONÇA, Márcia. Análise linguística no Ensino Médio: um novo olhar, um outro objeto. In: BUNZEN, Clecio; MENDONÇA, Márcia (org.) Português no Ensino Médio e formação do professor. São Paulo: Parábola, 2006. p. 198-226. MENDONÇA, Márcia. Análise linguística: por que e como avaliar. In: MARCUSCHI, Beth; SUASSUNA, Lívia (org) Avaliação em língua portuguesa: contribuições para a prática pedagógica. Belo Horizonte: Autêntica, 2007a. p. 95-110.

MENDONÇA, Márcia. Análise linguística: refletindo sobre o que há de especial nos gêneros. In: SANTOS, Carmi Ferraz; MENDONÇA, Márcia; CAVALCANTE, Marianne C. B. (org.) Diversidade textual: os gêneros na sala de aula. Belo Horizonte: Autêntica, 2007b. p. 73-88.

MORO, Daniela. O processo de alfabetização de refugiados sírios: proposta de material didático para o ensino de português como língua de acolhimento. 2019. 143 f. Trabalho de conclusão de curso. Universidade Federal do Pampa - Unipampa, Bagé, 2019.

NEVES, Maria Helena de Moura. Que gramática estudar na escola? Norma e uso na Língua Portuguesa. São Paulo: Contexto, 2004.

NUNES, Ana Margarida Belém; SILVA, Ana Margarida Carvalho Vaz da; SILVA, Helena Margarida Vaz Duarte Mendes. Ensino/aprendizagem de PLE a hispanófonos: 
A análise linguística intercultural em eventos de formação de professoras de Português como Língua de Acolhimento

algumas reflexões sobre o uso da preposição a. Disponível em: $<$ http://varialing.web.ua.pt/wp-content/uploads/2017/03/ANA Helena_Margarida.pdf $>$. Acesso em: 29 abr. 2020.

SCHLATTER, Margarete; COSTA, Everton Vargas da. Docência compartilhada como design de formação de professores de português como língua adicional. Calidoscópio, [s. l.], v. 18, n. 2, p. 351-372, maio-ago. 2020. Disponível em: $<\underline{\text { http:// }}$ revistas.unisinos.br/index.php/calidoscopio/article/view/ cld.2020.182.06>. Acesso em: 2 mar. 2021.

TORQUATO, Cloris Porto. Ensino de língua portuguesa, interculturalidade e políticas de letramento. Signum: estudos da linguagem, [s.l.], v. 19, n. 1, 2016. Disponível em: $<\underline{\mathrm{http} / /}$ www.uel.br/revistas/uel/index.php/signum/article/view/23199>. Acesso em: 2 mar. 2020.

TORQUATO, Cloris Porto. Ser estrangeiro num contexto acadêmico brasileiro nas vozes de estudantes PEC-G. In: FERREIRA, Aparecida de Jesus; JOVINO, Ione da Silva; SALEH, Pascoalina Bailon de Oliveira (org.). Um olhar interdisciplinar acerca de identidades sociais de raça, gênero e sexualidade. Campinas, SP: Pontes Editores, 2014. p. 201233.

TRAVAGLIA, Luiz Carlos. Gramática e interação: uma proposta para o ensino de gramática no $1^{\circ}$ e $2^{\circ}$ graus. São Paulo: Cortez Editora, 1995.

TRIPP, David. Pesquisa-ação: uma introdução metodológica. Educação e Pesquisa, São Paulo. v. 31, n. 3, p. 443 - 466, 2005. Disponível em: http://www.scielo.br/scielo.php?pid=S1517$97022005000300009 \&$ script $=$ sci_abstract\&tlng=pt. Acesso em: 2 mar. 2020. 